\title{
How to Measure Rhetorical Impact of Teaching and their Levels of Persuasion: A Neuro-rhetoric Approach
}

\author{
Lucio Cañete $^{1}$ - Hernán Diaz ${ }^{1}$. \\ Felisa Córdova ${ }^{1}$. Tania Soto ${ }^{1}$. \\ Eduardo Reinao $^{1}$. Fredi Palominos ${ }^{1}$
}

Received: 23 November 2015 / Revised: 25 November 2015 / Accepted: 27 November 2015 /

Published online: 14 December 2015

(C) Springer-Verlag Berlin Heidelberg 2015

\begin{abstract}
This paper explore the question about how persuasive is a person, a professor in our interest, depending on his/her rhetoric. Since persuasion is an act for amending the mind, a model to describe this intellectual entity in students consists of seven categories of elements in it: Quality, Quantity, Space, Time, Causality, Purpose and Law. According to the emphasis that the persuader places in each category of mental elements, he/she is classified in a rhetorical manner. The effect over the system of beliefs of a student caused by each rhetoric manner will be different depending on the way the new paradigm confront older or misunderstood previous classifications, organizations, and conceptualizations. Since the processing of a discourse occur mentally, not necessarily expressed by notorious disturbances in the behavior, we explore the way to measure the attentional impact of two lecturer: (i) a human being; and (ii) a computer machine, on the EEG activity of three listeners. We extracted the upper $25 \%$ of EEG signal intensity for the whole frequency $0.1-64 \mathrm{~Hz}$ range, to proceed to analyze the graphical data extracted from the time/frequency/intensity EEG spectrograms. Additional and supplementary on-field results indicate that teachers who prefer affect Causalities, Purposes and Laws; are the most persuasive.
\end{abstract}

Keywords Persuasion $\cdot$ Mind $\cdot$ Rhetoric $\cdot$ Electroencephalogram $\cdot$ Teaching

Lucio Cañete

lucio.canete@usach.cl

Hernán Diaz

hernan.diaz@usach.cl

1 Laboratory of Neurocognitive Engineering \& Laboratory of Neuromanagement, Department of Industrial Engineering, Faculty of Engineering, University of Santiago de Chile, Santiago, Chile 


\section{Introduction}

For university students, classroom, gymnasium, laboratory, workshop or whatever the place where the teaching-learning process takes place, that is their immediate ecosystem [1]. An essential element of this ecosystem is the teacher [2]. Indeed, it may lack the blackboard or desks, but not who leads the class, neither in a classroom nor in a college or field.

The relationships established in this ecosystem between learners and teachers may be of several types. The more traditional and natural is instructor-educated, but also in an industrial approach it is named server-served and sometimes at emotional level idol-fan and others. All these relationships are the result of the flow of information between teacher and student, being unidirectional (from the teacher to the student or vice versa) and bidirectional (from teacher to student and vice versa) [3].

A little studied relationship in university contexts is one that occurs in the student's belief system when the teacher alters it in order to achieve a different behavior that wouldn't be without the intervention of the teacher. When this change occurs in the beliefs of the student, this phenomenon is named as persuasion, which is in several areas a facilitator of the teaching-learning process [4-6].

In effect, the teacher in his/her role of educator and assuming full ethics in his/her performance must achieve in the students such behavior that maximizes learning. Since the baseline behavior is far from the desired by the teacher, he/she often tries changing the convictions by transitivity to alter this current behavior and ideally transform it into the desired. Success in the quest will depend on the persuasive rhetoric, which was supposed obey to the way in providing information to their students. That manner may be classifiable into a kind that will have certain magnitude on the change in the belief system [7].

\section{Objectives and Usefulness}

This work aims to find a way to quantify the cognitive impact of the persuasive act when two audios with very different rhetorical styles: (1) a text read by a human voice; and (2) a text read by a computer machine.

We look for identify a domain of changes where the rhetorical style can be detected and quantitatively measured in terms of the cognitive impact or stimulation of the brain during the act of hearing the audios.

Future experiments using specific voices of known teachers will allow them to know and measure his or her specific impact of the rhetorical style used in his/her classes. Since the variables which characterize the rhetoric are modifiable, professor will deduct the modifications that they should and can make in its own way of acting to improve the quality of education. 


\section{State of the Art}

\subsection{Introduction}

This work takes advantage of the latest advances in four major fields of human knowledge: Rhetoric, Ecology, Ergonomics and Neuroscience.

Rhetoric, the oldest of these fields of knowledge stands out naturally as the art of persuasion, one of the central concepts during the ongoing investigation. Ecology, field of human endeavor formally constituted in more recent times, offers its conceptual deal by regarding the ecosystem relations between persuaded and persuader, both immersed in a dynamic and complex environment. Ergonomics understood here in its broadest scope as the science of work and the later in turn as the ability to make changes, has a novel contribution to note that persuasion is essentially a change of convictions. Neuroscience not only contributes with a large theoretical base and accelerated technological advances but also with a diversity of ways to describe and quantify neural behavior.

\subsection{Rhetoric}

Rhetoric whose cradle is in Ancient Greece, but in the Middle Ages was established at the university level with the Trivium, a unique body of knowledge which comprised besides Grammar and Logic; now experiencing a rebirth in various human endeavors as was admitted at the First International Conference on Rhetoric and Interdisciplinary held in 2013 in the city of Mendoza Argentina. In this regard the highlighted crosscall of this world meeting was: “... a través de siglos el rico caudal de conceptos que enseñaron a organizar el lenguaje de la elocuencia, de la poesía y de las ciencias en cada época de la historia de Occidente, se une con las modernas propuestas de análisis del discurso, los estudios sobre argumentación o sobre la práctica persuasiva de las imágenes, ya en la propaganda política o en la penetrante persuasión para el consumo..." This statement finds a clear verification in persuasion campaigns through the media in order to achieve certain preferences or rejections about services and manufacturing, from a detergent to a candidate for public charge.

Exploring Rhetoric in teaching, interesting is the quantitative experimental work of Alexander and others in "Teaching as persuasion" [8], highlighting that metaphorically the teaching process is a way of persuading when personally students are committed to issues to learn. At university level, it highlights the work of four Australian educators entitled "Rhetorical and Educational Discourse" [9], especially such chapter labeled "Inventing the good teacher" where they regard the discursive deployment of teachers as part of their professional development: "Teachers and lecturers attempt to persuade their students that learning is a worthwhile activity."

\subsection{Ecology}

Ecology as a branch of biology initially dealt with the relationship between individuals and their environments, especially those of matter and energy. However, Dukas and 
other ecologists also include the information [10]. So, Cognitive Ecology is a subbranch recently emerged and in this article it has a particular interest because the whole teaching-learning process necessarily involves information flows between who learns and who teaches.

In this ecosystem context, to convince students that learning is rewarding activity (among other achievements), requires the teacher to mobilize various elements of the environment of his/her target student $[11,12]$.

\subsection{Ergonomics}

Persuasion is necessarily a change in the system of beliefs, the most important of all organizational systems as Toffler claimed in his book "The Adaptive Corporation" [13]. This change like another requires some work that is scientifically facilitated by the existence of a discipline that is dedicated specifically to work: Ergonomics.

Until nowadays Ergonomics does not have searched for keys in university teaching, but a very good tool for therapists has a full review of models and theories presented by Cameron in "A practitioner's guide to persuasion" [14]. This inventory of different thoughts about the persuasion is a rich conceptual database.

\subsection{Neuroscience}

This scientific discipline is attracting the attention of professionals from diverse fields. In this convergence of interests it highlights the development of procedures that aim to reveal the feelings of the people through non-invasive monitoring physiological signals when they face persuasion [15-19].

So close is the relationship between the behavior of the nervous system that reveals some emotional-cognitive status with the signals captured by these noninvasive observations, that such technology has interesting applications addressed in ecosystem points of view [20].

This position has a materialist basis in all phenomena, including mental, about each phenomenon can be observed because it has a physical support. So it is assumed that a system of beliefs will have a different brain configuration to another in the same person. Therefore, both systems may be observed and determine whether the beliefs changed [21]. That difference could hypothetically be noticed if a device that measures brain activity is provided in the head of a volunteer. This type of device is commercially available and consists of a headband with channel pairs that measure neural oscillations in frequency range of waves: Delta $(0-4 \mathrm{~Hz})$; Theta $(4-8 \mathrm{~Hz})$; Alpha $(8-13 \mathrm{~Hz})$, Beta $(13-30 \mathrm{~Hz})$ and Gamma $(>30 \mathrm{~Hz})$.

\subsection{Towards a Classification of Rhetoric}

Not only psychologists, politicians and professors have an own way to persuade which obeys different circumstances; but everyone because persuasion is a human phenomenon like any other, depends on a purpose and scenario. Given this premise that 
suggests a range of ways to persuade, it is required to identify certain kinds of rhetoric in a different universe.

This classification requires an examination of previous attempts made by science and its results achieved, so as to achieve a classification that meets three qualities: syntactic, semantic and praxis. The syntax requires the criterion of classification has its own internal coherence, while the semantics required keeping a correspondence between the model and observed reality. Praxis in turn, requires the classification can be carried out at the level of university teaching, which is the field of use of the ongoing investigation.

Geometrically it requires delimiting a small number of spheres within a certain rhetorical space. These spheres will contain the manners of persuasion. So this classification must be both exhaustive and exclusive: no manner should assign without of any sphere and no manner should assign (contained) in more than one sphere.

\subsection{Towards a Measurement of Persuasion}

Since each set of rhetorical ways clustered within a sphere has its own persuasive effect, it must quantify its effect. The route proposed for this achievement necessarily involves an experimental design.

Because persuasion is an intervention in mind, thanks to advances in neuroscience and artifactual available technology, such intervention can be measured. Indeed, there are currently a number of invasive and non-invasive instruments that capture changes in brain states, the "house of mind" [22]. A family of such devices that measure changes in the brain are the electroencephalographs (EEG), which willing discreetly on the person's head and connected wirelessly to a computer, enable record-level changes of the cerebral cortex, showing hence changes the person experiences [23].

Besides of be able to capture the brain activity from students through EEGs that would demonstrate differences in status related to the level of persuasion achieved, it is also possible to measure this ecosystem phenomenon through changes in the behavior of individuals to situations [24]. But as stated earlier, the problem of this classic form of measurement is the difficult isolation of other phenomena that affect behavioral change, such as incentives to do or not to do something, including the rewards or potential punishments involved [25].

\subsection{Classification of Rhetoric}

\subsubsection{The Relevant Classification}

A teacher can use to persuade the emotional part in a rational way. He/she can take oral rather than written media. He/she can talk about his/her work experience, academic career or family life to alter the beliefs of students. That is, the way that persuades can be classified from different points of view; but surely whatever the criterion for classifying, it must address the core issue: the way how she/he alters the convictions of students. 
In this respect, the mind of the target student acquires an inalienable role being necessary to address how the teacher intervenes in it to change the convictions. Traditionally rhetoric has classified as changes in the convictions based on various criteria [26-28]. For example, as the favorite argument (ethos, pathos and logos) as the frequency used for qualities in verbal expression (puritas, perspicuitas and ornatos), by gender related oratorio (judicial, forensic and demonstrative) and the use of trend rhetorical figures (alliteration, anaphora, irony, metaphor, hyperbole, epithets, etc.).

With all this taxonomy available in the literature, any teacher in function of he/she rhetorical display can self-classified into different spheres, each of them previously delimited according to some criterion. However, some non-traditional classification will be addressed, which necessarily preserve the ecosystem approach and the scope as universal as possible.

Following this guideline, Spirkin states in his book "Proisjoshdieniie soznaniia" that the immediate objective of the mind is the correct reproduction of reality in mind, while the mediate goal is the subordination of such reality to the human needs [29]. Given this premise, the teacher as persuader must make changes in mind so, that the resulting model of reality do not disagree the needs of the individual [30]. In others words, for changing the mind, the teacher only can act outside this abstract entity: in the environment of the student, so each environmental change must respect the needs of the student.

This reasoning is fully independent of sex, age, race, and other circumstantial qualities of student-teacher pair. Also, does not matter the administrative system of the university among other environmental variables that detract from universality classification. Here, only it is interesting such mental entities, which can be modified during the persuasive process without much matter if it resorts to the feelings or support tools.

\subsubsection{Modifiable Entities}

This same Russian scientist postulates a major issue for this research: the formation of "logical categories" in mind. Certainly some authors admit the combination of elemental entities in mind that give rise to others, without detailing what would be such entities. Spirkin is who is in charge of this matter through the formation and combination of something that in his own words he calls "raw material" and therefore, these entities are those the teacher ultimately alter in the mind of his pupil through environmental changes. The first logical category that identifies Spirkin is Quality: the existence of "something" of "a thing". The preservation of the quality of the object over a period makes this object the same.

Another logical category is Quantity, which is chronologically later than the "quantity". Indeed, because before comparing the number of objects, it must be identified the things that are being compared. Any calculation requires the qualitative identity. Simple, before counting it has to know that something is being told.

Also there is the phenomenon of motion; something that is here and now, later it is over there. So Spirkin identifies two new categories: Space and Time. 


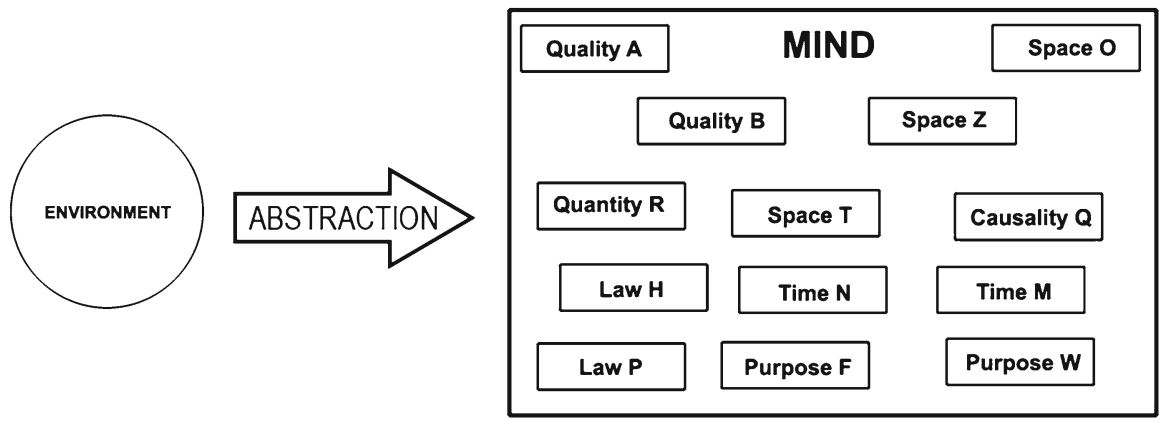

Fig. 1 Modeling the mind

Table 1 Frequencies of rhetorical manners preferred for most of the time by professors as they themselves declared

Unit (percentage)

\begin{tabular}{ll}
\hline Manners & Frequency $(\%)$ \\
\hline Quantity & 20 \\
Time & 15 \\
Space and time & 20 \\
Causality & 15 \\
Purpose & 10 \\
Law & 10 \\
Others & 10 \\
\hline
\end{tabular}

If anything moved from here to there it was because something caused such move, so the fifth category is called by Spirkin as Causality. The causality is conceived as an interaction between two or more objects.

Spirkin also identifies the category of Purpose, an intention observed in certain relationships of objects, especially when one of the objects observed in any interaction is a living being.

Finally Spirkin identifies the Law as a logical category because in his view the mind can classify universal relationships. This law result of the repetition of common causes and effects.

According to this Spirkiniana classification, the mind of any student can be modeled as shown in Fig. 1. This is a mental order in which these seven entities reflect the external environment.

\subsubsection{Rhetorical Manners}

Regarding the seven discussed categories, it follows that there are at least seven single ways to persuade and hundreds of other according different combinations of them. But as noted in the trials performed by a sample of professors at University of Santiago de Chile, themselves most time prefer only one or only two as it showed in Table 1.

The table shows that the most common manners used by the 25 professors of the sample are Quantity and Space-Time. Purpose, Law and other are the less frequent for persuading. 


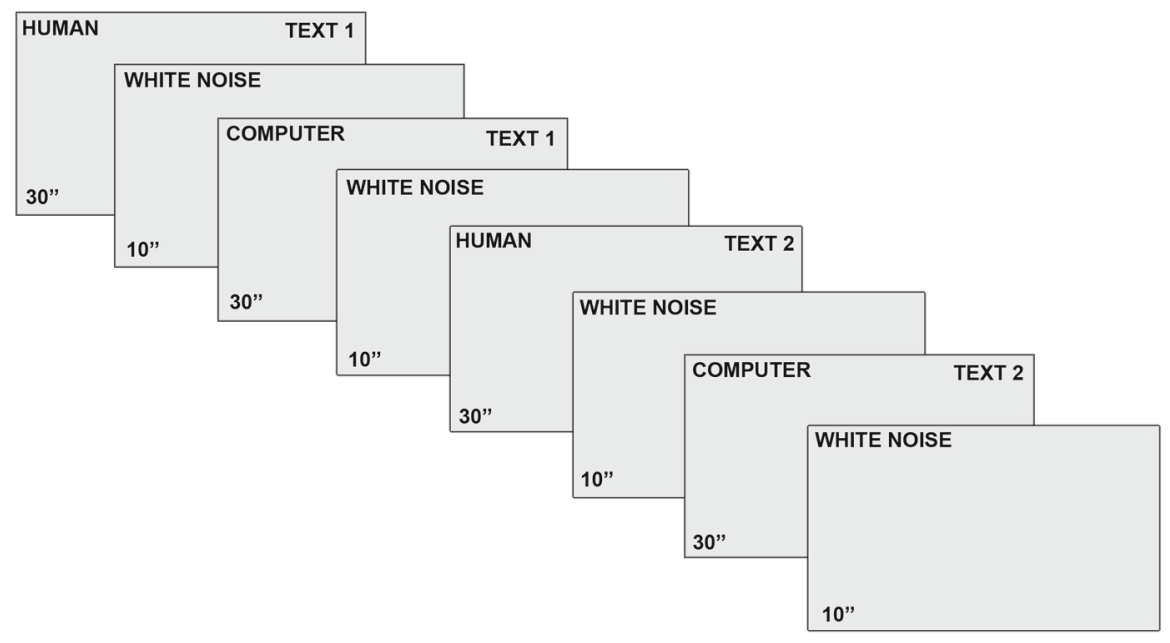

Fig. 2 Experimental procedure

\section{Experiment}

To study the impact of rhetorical manners on the brain activity of a listener we implemented a simple test that consisted in to hear an audio sequence of discourses of $30 \mathrm{~s}$ duration each, punctuated by 10s of white noise in between them as shown in Fig. 2 .

First discourse (HUMAN) was read by a human voice in a natural, not forced or especially rhetoric manner more than a normal human spoken language.

The text of the second discourse (COMPUTER) was the same that was presented in the first instance but now the text was read by a computer. As mentioned before, each discourse trial lasted $30 \mathrm{~s}$, with ten second of white noise between testing discourses. Audio tracks were listened through in-ear headphones at a normal volume.

The experiment was made in a sequence of two repetitions, applying the same protocol but changing the text of the discourse in the second trial (Fig. 2).

During the experiment, the EEG activity of subjects $(\mathrm{N}=3)$ was recorded at $164 \mathrm{~Hz}$ sample rate for 16 channels located at standard 10/20 system placed over the scalp (AF3, F3, F7, FC5, T7, P7, O1 for LEFT hemisphere; and AF4, F4, F8, FC6, T8, P8, O2, for RIGHT hemisphere) (Fig. 3). We used Emotiv Epoc $囚$ braininterfase machine [31,32] to capture EEG. Preprocess and data analysis processing used EEGLAB toolbox [33] running on MatLab 2008a platform.

Artifact cleaning was made by independent component analysis (ICA) assisted by ADJUST toolkit [34]. Data series was normalized and to be more specific in our visual and image analysis, we used only the higher $25 \%$ of the EEG signal power. Filtering by intensity allows dissect the signal in different ranges of EEG power that can be analyzed independently. For this upper $25 \%$ of the signal power we obtained the spectrograms depicting the behavior of the frequency (y-axes) components of the signal along time (x-axes). When the signal is not filtered by intensity, a grayscale of 255 values indicates de relative value of the intensity of a given frequency range in 
Fig. 3 EEG Emotiv

brain-computer interface and channels location

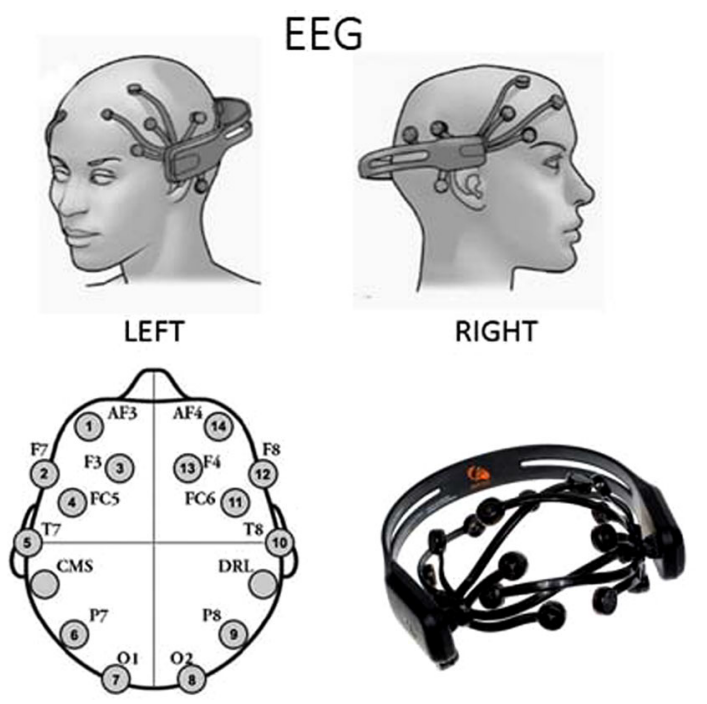

a specific time interval. In our case, having filtering and extracting the upper part of the signal with maximum values, the spectrograms obtained resemble more a digital map of activity than an oscillatory analogic process. We analyzed these spectrograms using ImageJ software.

We describe the whole range of frequency activity that we were able to analyze according to Nyquist restriction, so $0.1-64 \mathrm{~Hz}$ spectrograms were depicted to visualize the general behavior of the frequency components of the EEG during the experiment along time.

\section{Results}

\subsection{Spectrographic Analysis}

Figure 4 depicts the spectrogram obtained for one (DJV) out of the three subjects during the experiment.

As seen in the spectrogram for DJV, when plotting the CH1, left-frontal EEG channel, a strong drop of the maximum activity is observed between 4 and $32 \mathrm{~Hz}$, in conjunction with the second presentation of the computer reading text (Fig. 4).

The figure also reveals that for the previous presentations a permanent strong and dense activity is present in the whole span of the spectrum ranging from 0.1 to $32 \mathrm{~Hz}$ and a second strong, but less dense area, corresponding to gamma band. At this level of visualization analysis, for this subject, gamma band appear just slightly affected in a rather constant decreasing activity along the experiment.

Another conspicuous element is a much defined component of frequency lying around the limit between beta and gamma band $(\sim 30 \mathrm{~Hz})$ which appears to be slightly rising in frequency from 30 to $34 \mathrm{~Hz}$ along the experiment. 


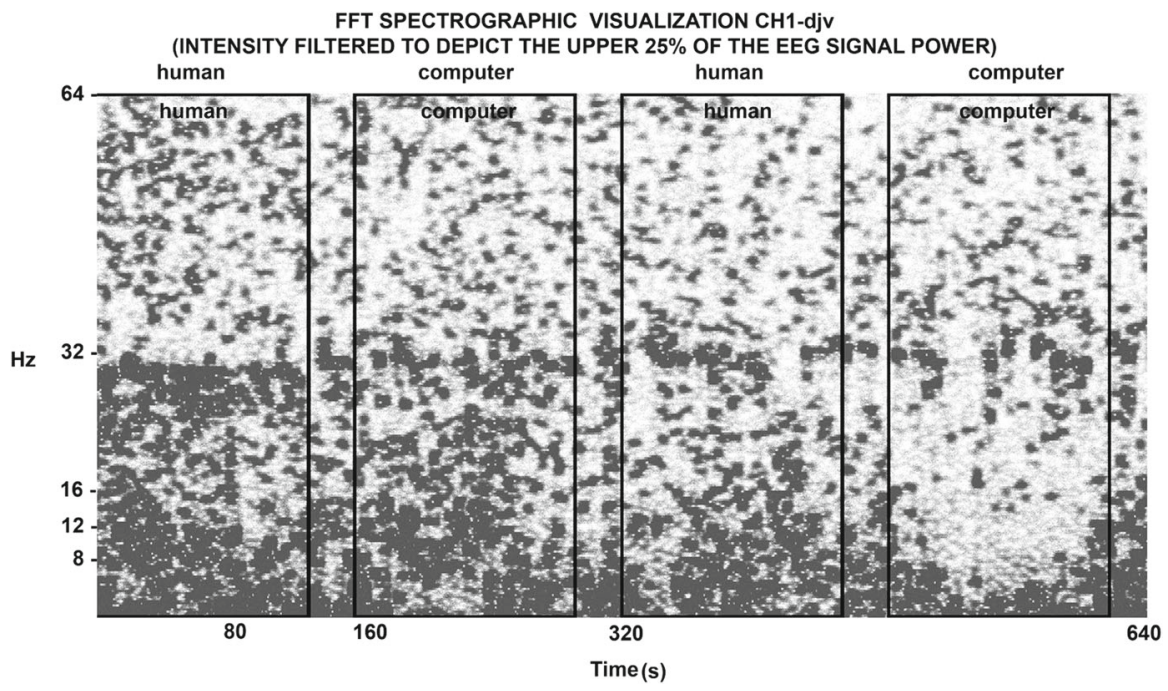

Fig. 4 EEG (0.1-64 Hz) spectrogram of frontal left channel $(\mathrm{CH} 1)$, subject DJV during the whole experiment

For the same plot $\mathrm{CH} 1-$ djv, Fig. 5 depicts density activity profile for EEG gamma, beta, alpha, and delta-theta bands across the experiment. Variation is expressed in grayscale values $(0=$ Black; $255=$ White $)$. Black area of graphs represents EEG activity density, while white area represents non-activity density.

Plots reveal that for DJV, alpha band is the most sensitive to the second presentation of COMPUTER reading, trend that is also followed by beta band that shows a regular decrease of the activity density along the experiment. Nor delta-theta nor gama band are strongly affected.

\subsection{Intra Individual Differences}

At the intra-individual level we find differences in the behavior of the EEG when comparing three different areas of the brain cortex: (i) Left and Right Frontal: CH1/CH14; (ii) L\&R Temporal: CH5/CH10; and iii) L\&R Occipital: CH7/CH8.

For subject DJV left and right frontal areas are more sensitive to the second presentation of the computer voice, while temporal and occipital areas are not strongly affected (Fig. 6). The same permanent frequency component referred when describing DJV CH1 spectrogram, slowly scaling along $30 \mathrm{~Hz}$, is present in the three brain areas and hemispheres inspected. Temporal areas are more densely composed during the whole experiment and along the whole frequency range, in a rather homogeneous distribution. A general but coincident slightly drop in the activity is seen in the last part of the experiment in the three areas but much more clearly manifested in the frontal area, especially in the left hemisphere. 

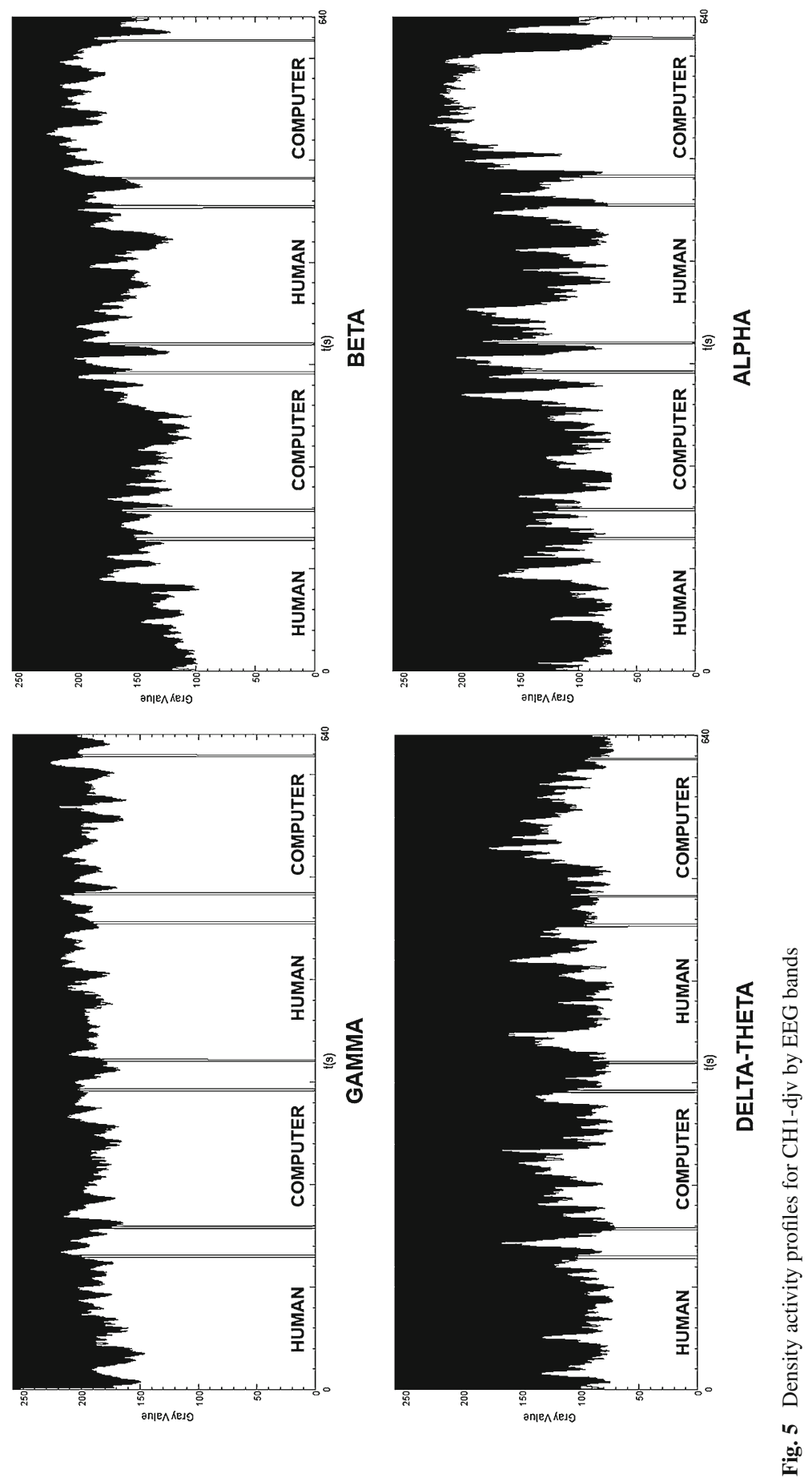


\section{FFT SPECTROGRAPHIC VISUALIZATION \\ FRONTAL (CH1/CH14) \\ TEMPORAL (CH5/CH10) \\ OCCIPITAL (CH7/CH8)}

\section{DJV}

$\mathrm{CH} 1$

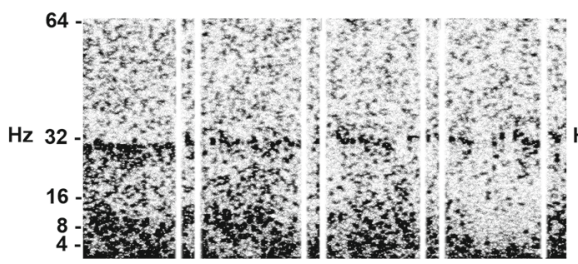

CH5

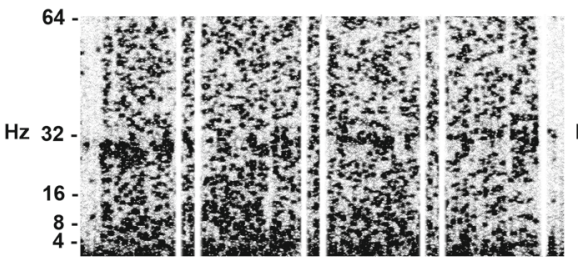

$\mathrm{CH} 7$

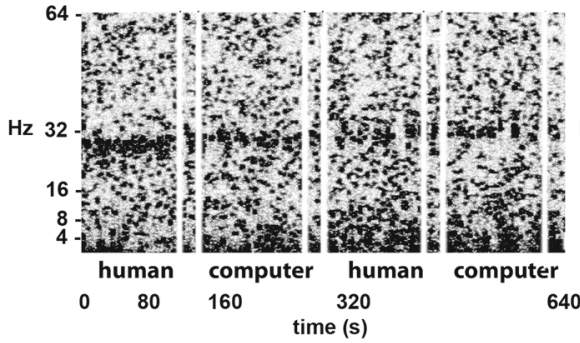

$\mathrm{CH} 14$

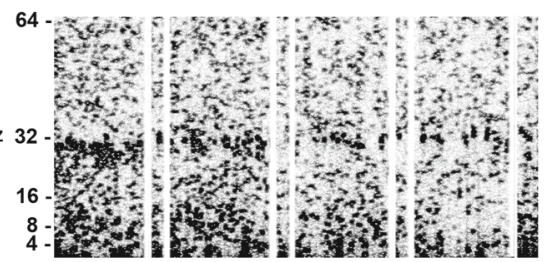

$\mathrm{CH} 10$

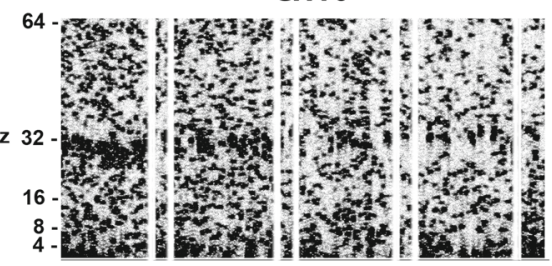

$\mathrm{CH} 8$

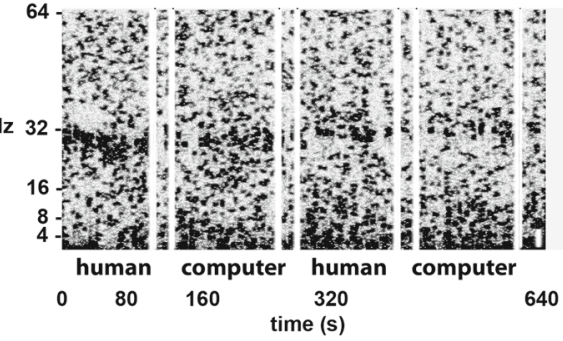

Fig. 6 Spectrograms of three brain areas (frontal, temporal and occipital) of subject DJV to compare distribution and density of the brain activity during the experiment. White vertical lines indicate the start and the end of the sequence of stimulus or white noise inter-stimulus punctuation

\subsection{Inter Individual Differences}

We make the common assumption that people have a different degree of acceptability before a seductive proposal which consist in a decision making promoted by a third one. Finally the impact of the rhetorical style of the seducer depends on the degree of acceptability or sensibility of the target subject in front of a supposedly convincing display of arguments and behavior. In this way we can find people more or less permissive or sensitive to changes in rhetorical manners.

Figures 7 and 8 depict the same kind of spectrograms presented in Fig. 6, but for the other two subjects (JMC and SMI). 


\section{FFT SPECTROGRAPHIC VISUALIZATION \\ FRONTAL (CH1/CH14) \\ TEMPORAL (CH5/CH10) \\ OCCIPITAL (CH7/CH8)}

\section{JMC}
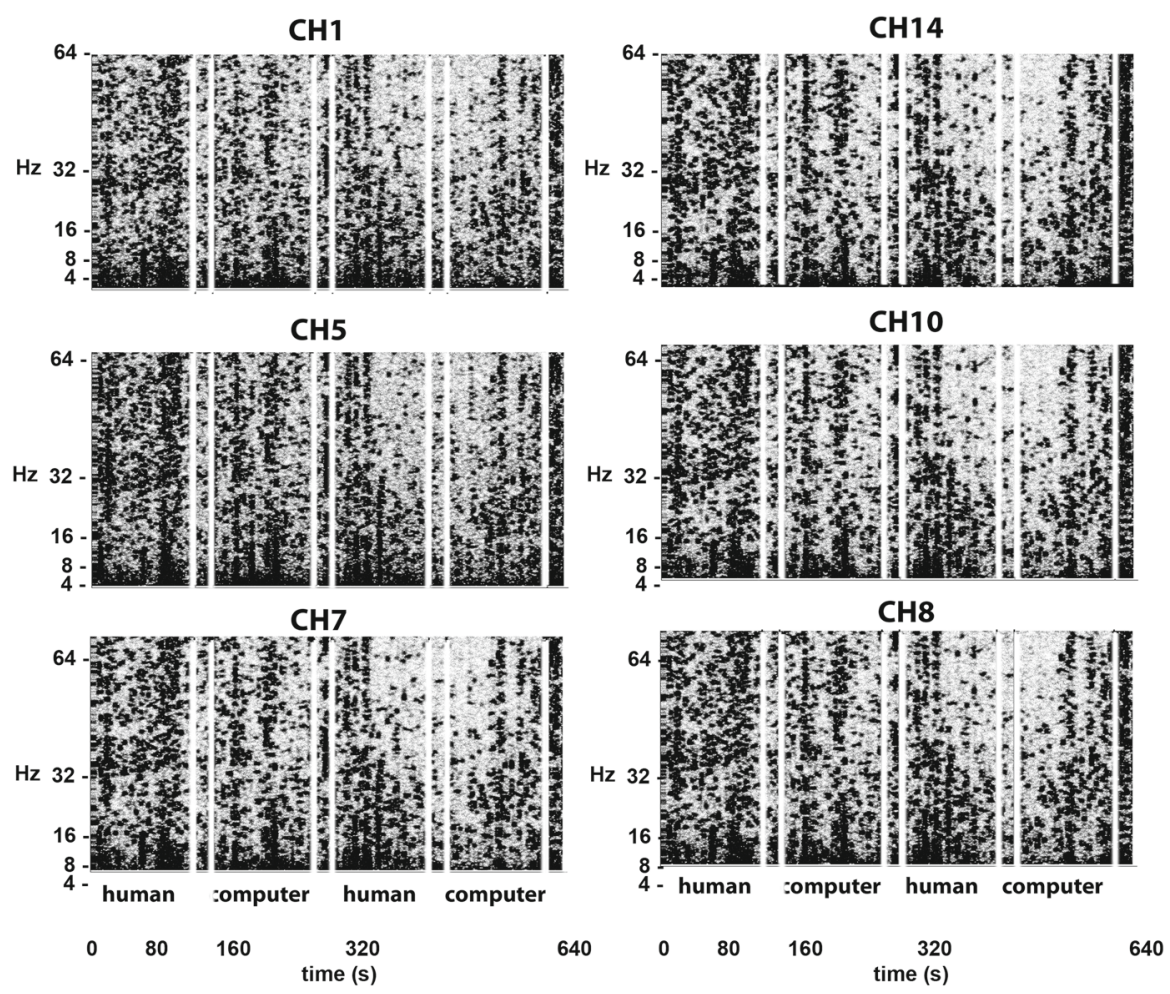

Fig. 7 Spectrograms of three brain areas (frontal, temporal and occipital) of subject JMC to compare distribution and density of the brain activity during the experiment

JMC subject shows a decrease of maximum activity density starting around the middle of the second HUMAN voice presentation, and spanning until the mid-part of the second COMPUTER voice reading. But, in contrast to DJV, the decrease in the activity here includes a pronounced long range gamma band drop together with part of the beta band, which is mainly affected at high beta range. Less dense regions are equally present in the three brain areas and hemispheres under study and its presence is more evident than in DJV subject. We also observe the almost complete absence of the circa-30 Hz activity running across the experiment observed in subject DJV.

Finally subject SMI does not respond distinctively to a specific part of the experiment presenting a very similar pattern of response during the whole presentation. In a 


\section{FFT SPECTROGRAPHIC VISUALIZATION \\ FRONTAL (CH1/CH14) \\ TEMPORAL (CH5/CH10) \\ OCCIPITAL (CH7/CH8)}

\section{SMI}

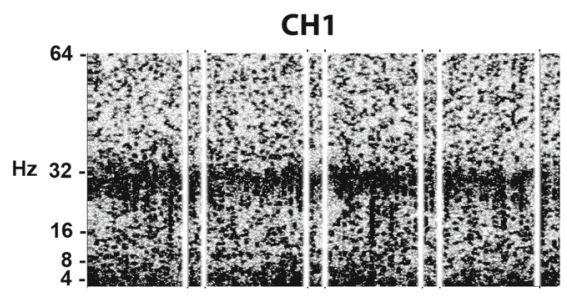

CH5

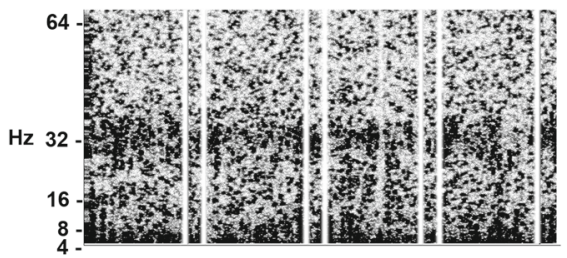

$\mathrm{CH} 7$

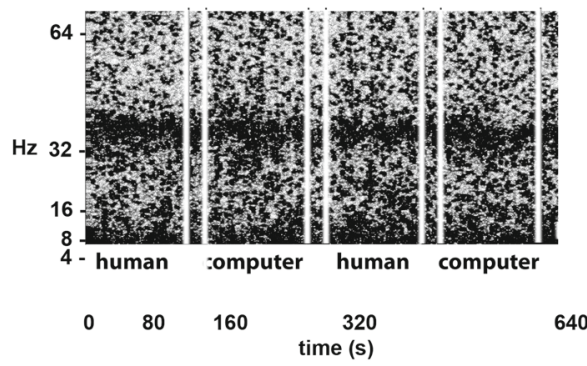

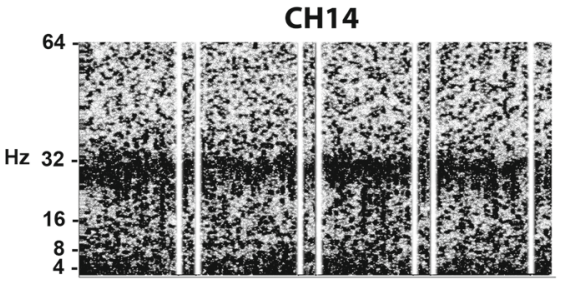

CH10

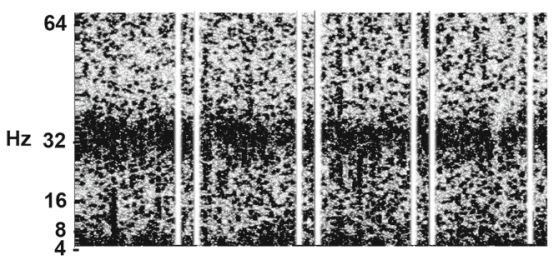

$\mathrm{CH} 8$

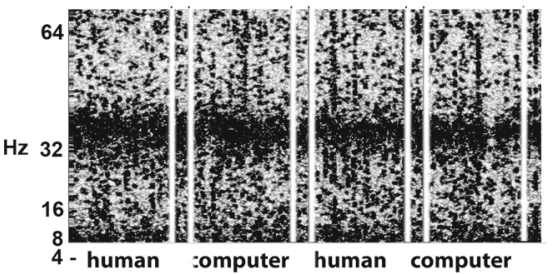

40

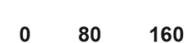

160
640

Fig. 8 Spectrograms of three brain areas (frontal, temporal and occipital) of subject JMC to compare distribution and density of the brain activity during the experiment

similar way as DJV, a strong and consistent activity in upper beta $(25-30 \mathrm{~Hz})$ is also observed in SMI along the whole experiment.

When comparing gamma activity among three subjects, Fig. 9 depict density activity profiles of the three subjects, only for the gamma respond to the second presentation of the COMPUTER voice.

Different patterns of activity in front of the same stimulus characterize the response of the gamma band of the three individuals. 

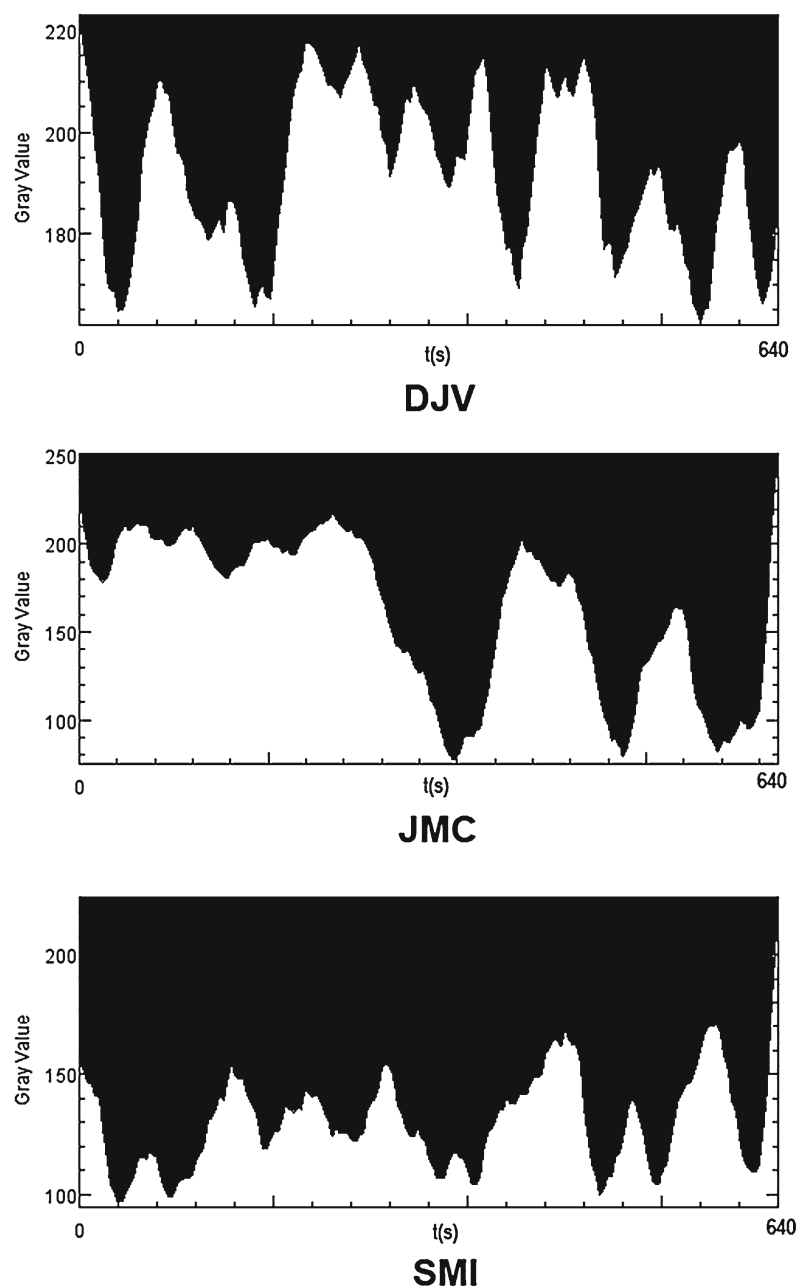

Fig. 9 Gamma band density activity profile response concomitant to the second presentation of COMPUTER voice

\section{Conclusions}

This research highlights the underlying process of teaching persuasion of a professor in his/her students, in the framework of rhetoric and the art of convincing people by mean of behavioral and linguistic display.

A good professor endowed with suitable rhetoric does not need "carrot or stick" to change certain unwanted behaviors in their students. Certainly the ethical aspects must be starring because a persuader may influence for good or ill.

Teacher's survey results showed six manners or spheres where each professor can be classified according to the mental elements that he/she preferably change. Since each way has its indicator of success, the teacher can also estimate his/her corresponding 
persuasive level, being able to modify its own style, if he/she has the means, to a more successful manner of rhetorical teaching.

Since every persuasion is an alteration of the convictions, it must be consonant with the belief system that is disturbing. Maybe that is because the three most successful manners (Causality, Purpose and Law) are those which require greater knowledge of the ecology of mind due to it represents the worldview of who is persuaded.

To test some simple intuitions about the effect of rhetoric on the EEG phenomenology, we exam a simple condition in which a human voice and a computer generated voice are alternatively presented to a subject. At the same time an EEG recording were captured for subsequent analysis.

Results show that it is possible to detect and quantify the effect of the rhetorical impact on the brain.

By mean of implement a spectrographic visualization and analysis of the EEG signal we mapped the time course of the brain activity and density distribution along the experiment, revealing intra- and inter-individual differences and also some consistencies between individuals.

Results showed that some areas of the subject's brains behave with more sensitivity according to the changes in the rhetorical component of the listened discourses. Other areas appear to be more resilient and barely affected by the stimulus sequence, while some common elements are also observed.

Spectrographic analysis allows us to have a panoramic view of the behavior of the frequency components of the EEG signal along the whole experiment. Assisted by filtering the signal by power slices a clean and digital-like representation of the EEG was obtained. The quantitative analysis of these images increasing resolution for better characterization of the phenomena, while setting future experimental condition more similar to a real performing class including other variables affecting the ergonomic of the environment [35].

Acknowledgments A foundational work of this research was presented at the International Conference on Information Technology and Quantitative Management (ITQM 2015), Rio, Brazil, July 21-24, 2015 (see Procedia Computer Science, Volume 55, 2015, Pages 28-34, 3rd International Conference on Information Technology and Quantitative Management, ITQM 2015). This work was supported by 061317CG DICYT Project at University of Santiago de Chile.

\section{References}

1. Peng JE (2012) Towards an ecological understanding of willingness to communicate in EFL classrooms in China. System 40(2):203-213

2. Fan FA (2012) Teacher: students' interpersonal relationships and students' academic achievements in social studies. Teach Teach 18(4):483-490

3. Gecer A (2013) Lecturer-Student communication in blended learning environments. Educ Sci 31(1):362-367

4. Hennessey MN, Higley K, Chesnut SR (2012) Persuasive pedagogy: a new paradigm for mathematics education. Educ Psychol Rev 24(2):187-204

5. Bowles R, O'Sullivan M (2012) Rhetoric and reality: the role of the teacher in shaping a school sport programme. Phys Educ Sport Pedag 17(3):303-316

6. Fagundez T, Castells M (2012) Study of the argument in university physics classes: a rhetorical perspective. Enseñanza de las Ciencias 30(2):153-173 
7. Corbett J, Connors R (1998) Classical rhetoric for the modern student, vol 4. Oxford University Press, New York

8. Alexander $\mathrm{P}$ et al (2002) Teaching as persuasion. Teach Teach Educ 18(7):795-813

9. Edwards R et al (2004) Rhetoric and educational discourse. RoutledgeFalmer, London

10. Dukas R (2009) Cognitive ecology. University of Chicago Press, Chicago

11. Hikins JW, Cherwitz RA (2010) The engaged university: where rhetorical theory matters. J Appl Commun Res 38(2):115-126

12. McConnell KF (2010) An appreciation of the kind of rhetoric we learn in school: an institutional perspective on the rhetorical situation and on education. Q J Speech 96(3):278-299

13. Toffler A (1984) The adaptive corporation. McGraw-Hill, London

14. Cameron K (2009) A practitioner's guide to persuasion. Patient Educ Counsel 74(3):309-317

15. Mays C, Jung J (2012) Priming terministic inquiry: toward a methodology of neurorhetoric. Rhetoric Rev 31(1):41-59

16. Jack J, Appelbaum LG (2010) "This is your brain on rhetoric": research directions for neurorhetorics. Rhetoric Soc Q 40(5):411-437

17. Craig AW, Loureiro YK, Wood S (2012) Suspicious minds: exploring neural processes during exposure to deceptive advertising. J Mark Res 49(3):361-372

18. Klucharev V, Smidts A, Fernandez G (2008) Brain mechanisms of persuasion: how expert power modulates memory and attitudes. Soc Cogn Affect Neurosci 3(4):353-366

19. Jack J (2010) What are neurorhetorics? Rhetoric Soc Q 40(5):405-410

20. Duizabo P (1991) Use of cognitive ergonomics in the neurosciences. Presse Med 20(25):1156

21. Pruchnic J (2008) Neuro rhetorics: cybernetics, psychotropics, and the materiality of persuasion. Configurations 16(2):167-197

22. Cavoukian A, Chibba M, Stoianov A (2012) Advances in biometric encryption: taking privacy by design from academic research to deployment. Rev Policy Res 29(1):37-61

23. British Neurosciences Association (2003) Neuroscience: science of the brain. Liverpool

24. Purves D et al (2010) Hardwired behavior what neuroscience reveals about morality. Cambridge University Press, New York

25. Frank R (2009) Microeconomics and behavior, 8th edn. McGraw-Hill, London

26. Gros A (2012) Rhetorical style: the uses of language in persuasion. Oxford University Press, New York

27. Kraus M (2011) How to classify means of persuasion: the rhetoric to Alexander and Aristotle on Pisteis. Rhetorica 29(3):263-279

28. Garver E (2009) Aristotle on the kinds of rhetoric. Rhetorica 27(1):1-18

29. Spirkin A (1965) El Origen de la conciencia humana. Platina/Sitilcograf, Buenos Aires

30. Cooper J (2007) Cognitive dissonance: fifty years of a classic theory. SAGE Publications Ltd, London

31. Mousikou Badcock N P, Mahajan Y, De Lissa P, Thie J, McArthur G (2013) Validation of the Emotiv EPOC $^{\circledR}$ EEG gaming system for measuring research quality auditory ERPs. PeerJ 1:e38

32. Preece Badcock N KA, de Wit B, Glenn K, Fiede N, Thie J, McArthur G (2015) Validation of the Emotiv EPOC EEG system for research quality auditory event-related potentials in children. PeerJ 3:e907

33. Delorme A, Makeig S (2004) EEGLAB: an open source toolbox for analysis of single-trial EEG dynamics including independent component analysis. J Neurosci Methods 134(1):9-21

34. Jovicich Mognon A J, Bruzzone L, Buiat M (2010) ADJUST: an automatic EEG artifact detector based on the joint use of spatial and temporal features. Psychophysiology 48:229-240

35. Palominos Cañete L F, Díaz H, Córdova F, Cifuentes F (2015) Relationship between the ergonomic state of the classroom measured in energy units and the well-being of students observed by non-invasive instrumentation. Procedia Computer Science, Vol. 55, 2015, pp 28-34, 3rd International Conference on Information Technology and Quantitative Management, ITQM 